\title{
The role of $\mathrm{CCN} 2$ in cartilage and bone development
}

\author{
Satoshi Kubota $\cdot$ Masaharu Takigawa
}

Received: 20 January 2011 / Accepted: 21 January 2011 / Published online: 14 February 2011

(C) The Author(s) 2011. This article is published with open access at Springerlink.com

\begin{abstract}
CCN2, a classical member of the CCN family of matricellular proteins, is a key molecule that conducts cartilage development in a harmonized manner through novel molecular actions. During vertebrate development, all cartilage is primarily formed by a process of mesenchymal condensation, while $\mathrm{CCN} 2$ is induced to promote this process. Afterwards, cartilage develops into several subtypes with different fates and missions, in which CCN2 plays its proper roles according to the corresponding microenvironments. The history of CCN2 in cartilage and bone began with its re-discovery in the growth cartilage in long bones, which determines the skeletal size through the process of endochondral ossification. $\mathrm{CCN} 2$ promotes physiological developmental processes not only in the growth cartilage but also in the other types of cartilages, $i$. e., Meckel's cartilage representing temporary cartilage without autocalcification, articular cartilage representing hyaline cartilage with physical stiffness, and auricular cartilage representing elastic cartilage. Together with its significant role in intramembranous ossification, CCN2 is regarded as a conductor of skeletogenesis. During cartilage development, the CCN2 gene is dynamically regulated to yield stage-specific production of $\mathrm{CCN} 2$ proteins at both transcriptional and post-transcriptional levels. New functional aspects of known biomolecules have been uncovered during the course of investigating these regulatory systems
\end{abstract}

S. Kubota $(\bowtie) \cdot$ M. Takigawa $(\bowtie)$

Department of Biochemistry and Molecular Dentistry,

Okayama University Graduate School of Medicine,

Dentistry and Pharmaceutical Sciences,

2-5-1 Shikata-cho, Kita-ku,

Okayama 700-8525, Japan

e-mail: kubota1@md.okayama-u.ac.jp

e-mail: takigawa@md.okayama-u.ac.jp in chondrocytes. Since CCN2 promotes integrated regeneration as well as generation (=development) of these tissues, its utility in regenerative therapy targeting chondrocytes and osteoblasts is indicated, as has already been supported by experimental evidence obtained in vivo.

Keywords CCN2 CTGF · Chondrocyte · Cartilage · Endochondral ossification $\cdot$ Bone

\section{Re-discovery of CCN2 in growth cartilage}

CCN2, also known as connective tissue growth factor (CTGF), was originally identified in 1991 as a plateletderived growth factor-related protein with mitogenic activity toward fibroblasts (Bradham et al. 1991), which finding prompted the initial name given to this molecule. Afterwards, at least 8 different names were given to this single molecule (Perbal and Takigawa 2005), until the unified nomenclature was finally proposed in 2003 (Brigstock et al. 2003). As a result, CCN2 was given as the name for this second-oldest known molecule among the $6 \mathrm{CCN}$ family members, based on this new terminology.

During this emerging period, a gene segment that was specifically expressed in hypertrophic chondrocytes in the mouse growth plate was cloned from the cDNA obtained from human chondrocytic HCS-2/8 cells (Takigawa et al. 1989) via the differential display PCR method (Nakanishi et al. 1997). This molecular clone was designated hypertrophic chondrocyte-specific gene 24 (Hcs-24). Nucleotide sequence analysis of this clone revealed that Hcs-24 was identical to Ctgf. Starting from this re-discovery of CTGF in growth plate cartilage and a human chondrocytic cell line, critical roles of $\mathrm{CCN} 2$ in chondrocytes have been uncovered up to today. 


\section{Molecular action of CCN2 in cartilage}

Cartilage is a connective tissue characterized physically by its proper elasticity. This tissue is avascular, and the cells are surrounded by a vast amount of extracellular matrix (ECM). Therefore, signal transmission to/from chondrocytes generally occurs via the interaction of signaling factors with cartilaginous ECM molecules, which is referred to as a matricrine molecular action (Chen and Lau 2009). In such a microenvironment, an extracellular information network is formed on the basis of the ECM scaffold. For the harmonized formation and maintenance of this network, CCN2 is thought to be required, because of its novel structure and functionality (Kubota and Takigawa 2007).

$\mathrm{CCN} 2$ is recognized as a multifunctional key player in the development of mesenchymal tissues and is also known to be involved in pathological conditions represented by various fibrotic diseases and malignancies (Perbal and Takigawa 2005; Leask et al. 2009; Chen and Lau 2009; Chen et al. 2011). Similar to the other CCN family members, CCN2 is composed of 4 distinct modules connected in tandem, which are insulin-like growth factor binding protein-like (IGFBP), von Willebrand factor type $\mathrm{C}$ repeat (VWC), thrombospondin type 1 repeat (TSP1), and C-terminal cystine knot (CT) modules (Perbal 2004; Leask and Abraham 2006, Kubota and Takigawa 2007; Chen and Lau 2009). Since all of these modules are highly interactive with a number of other molecules, CCN2, as a 4-handed matricellular conductor, is able to manipulate the behavior of these counterparts to integrate their actions (Fig. 1). Indeed, binding of CCN2 to ECM molecules such as aggrecan, heparan sulfate proteoglycans, and fibronectin (Aoyama et al. 2009; Gao and Brigstock 2004; Nishida et al. 2003; Hoshijima et al. 2006); to cell-surface receptors such as integrins, low-density lipoprotein receptor-related protein 1 (LRP1) and Trk A (Jedsadayanmata et al. 1999; Segarini et al. 2001; Kawata et al. 2006; Asaumi et al. 2000; Wahab et al. 2005); to growth factors such as transforming growth factor $\beta$ (TGF- $\beta$ ), bone morphogenetic proteins (BMPs), and vascular endothelial growth factor (VEGF) (Abreu et al. 2002; Maeda et al. 2009; Inoki et al. 2002); and even to certain CCN family members has been proven experimentally (Hoshijima et al. 2011). It should be noted here that all of the molecules mentioned above are present in cartilage. As detailed in the following sections of this review, $\mathrm{CCN} 2$ plays critical roles in cartilage development, maintenance, and regeneration via complex interactions with these molecules.

\section{Classification of cartilage in vertebrates}

During the course of evolution, cartilage appeared to furnish the body with an endoskeleton. In early vertebrates,

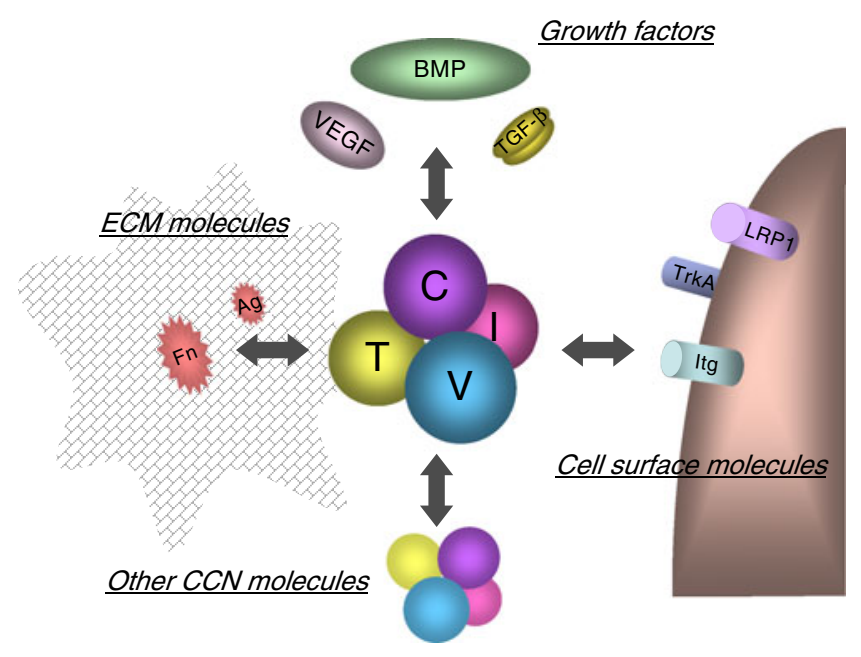

Fig. 1 Molecular action of $\mathrm{CCN} 2$ in cartilage. CCN2 molecule represented by the complex with 4 spheres in the center interacts with a number of biomolecules in different categories, which results in the integrated manipulation of extracellular signaling. The letters "I," "V," "T," and "C" on the spheres denote insulin-like growth factor-like module, von Willebrand factor type $\mathrm{C}$ repeat, thrombospondin type 1 repeat and $\mathrm{C}$-terminal cystine knot module, respectively. Growth factors interacting with $\mathrm{CCN} 2$ include transforming growth factor beta (TGF- $\beta$ ), bone morphogenetic proteins (BMPs) and vascular endothelial growth factor (VEGF). Binding between CCN2 and cartilaginous ECM molecules, such as fibronectin (Fn) and aggrecan, is indicated. Several cell-surface receptors present on chondrocytes as represented by integrins (Itg), low-density lipoprotein receptor related protein 1 (LRP-1) and Trk A are known to directly interact with $\mathrm{CCN} 2$. Of note, recent investigation is revealing the interaction of $\mathrm{CCN} 2$ with another CCN family member, as well as with itself

as represented by lampreys, the endoskeleton is totally composed of cartilaginous tissues; whereas major portions of skeletal parts are eventually replaced with calcified bone tissue in later vertebrates (Kubota and Takigawa 2007). However, as development repeats evolution, most of our skeletal parts are initially formed as cartilage anlagen, followed by the growth of the cartilage and gradual replacement with bone (Karaplis 2002). However, quite limited parts are left uncalcified to form tissues/organs with the physical property of elasticity. From this point of view, cartilage can be roughly classified into 2 distinct classes: temporary and permanent cartilages (Fig. 2). Among the temporary cartilages, most of them undergo growth and direct replacement with bone, which process is typically observed in the endochondral ossification of long bones (Karaplis 2002); whereas the others simply disappear during the development of the corresponding bones (Couly et al. 1993). Meckel's cartilage and the notochord represent the latter class of temporary cartilages. In the case of permanent cartilage, the relevant tissues can be classified into 3 groups based on their physical property and ECM composition (Fig. 2). The first group is that with physical stiffness, which is represented by the articular cartilage 
Typical

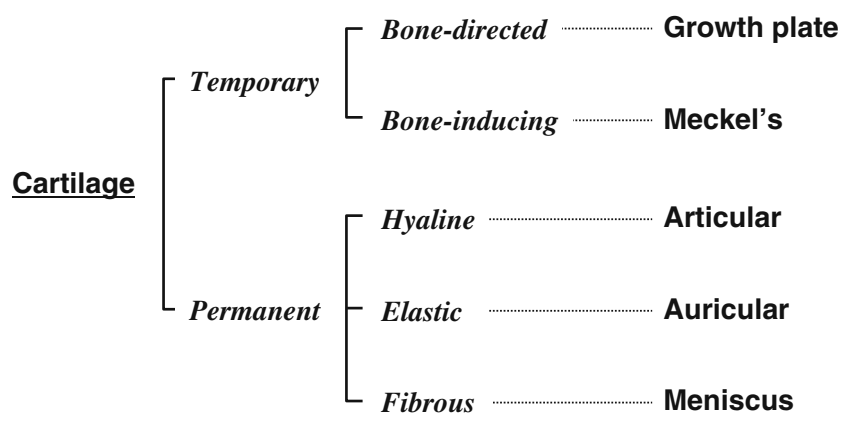

Fig. 2 Classification of cartilage present in vertebrates. Temporary cartilage appears during development to accomplish skeletal formation and growth. A class of temporary cartilage, here termed bone-directed cartilage, itself is mineralized to become bone under the collaboration with osteoblasts and vascular endothelial cells. In the case of boneinducing cartilage, bone is formed independently at a space in close proximity. Permanent cartilage is formed and maintained to add elasticity and stiffness required in certain organs. Based on the physical property, histological characteristics, and ECM composition, permanent cartilage can be classified as hyaline, elastic or fibrous

found in the joints. The second group is characterized by a high level of elasticity, typically observed in ears; and the third group is rich in collagen fibers, adding flexibility to this tissue. Surprisingly, CCN2 has been shown to promote the development of most of these different types of cartilages, as described below.

\section{CCN2 in the growth plate}

In vertebrates, all of the long bones and major skeletal components develop through a process known as endochondral ossification, whereas craniofacial bones and other minor skeletal parts are constructed via intramembranous ossification or via an intermediate/mixed process of the two (Karaplis 2002). During this process, the growth plate chondrocytes inside the bone or cartilage anlagen play a major role, particularly in bone growth. Therefore, endochondral ossification can be regarded as a critical biological process that determines the body height, in which CCN2 plays a central role to conduct all of the events of this process (Fig. 3).

After the formation of cartilage anlagen, growth plates are formed near both ends, facing the ossification centers. Here, chondrocytes undergo a series of differentiation steps to grow and calcify the bones. Along with bone growth, resting chondrocytes in a deep zone of the cartilage begin to proliferate and undergo maturation, producing a cartilaginous ECM including type II collagen and aggrecan as components, in order to support the bone growth. At the final step, chondrocytes differentiate into the hypertrophic chondrocytes that trigger matrix vesicle-mediated calcification, while producing type $\mathrm{X}$ collagen and matrix metal- loproteinase (MMP)-13, and are then removed by phagocytosis by chondroclasts and/or apoptosis. Thereafter, osteoblasts and vascular endothelial cells are recruited to replace the hypertrophic layer of growth cartilage with bone tissue. As mentioned in a previous section, CCN2 was initially found specifically in the hypertrophic layer of the growth plate; and later, pre-hypertrophic chondrocytes were confirmed to be the major producer of CCN2. Since CCN2 is a matricellular protein, it can be stored in, and infiltrate through, the ECM. In fact, immunohistochemical staining of CCN2 shows strong signals in pre-hypertrophic and hypertrophic layers and significant signals in proliferating layer and cartilage-bone junction in the growth plate. Of importance, it has also been shown that CCN2 promotes the proliferation and differentiation of osteoblasts, osteoclasts, and vascular endothelial cells (Nishida et al. 2000; Safadi et al. 2003; Shimo et al. 1999; Nishida et al. 2011), as well as the chondrocytes themselves in vitro (Nakanishi et al. 2000). Additionally, the growth plate-produced CCN2 may be a possible source of the CCN2 accumulated in platelets (Cicha et al. 2004; Kubota et al. 2004; Sumiyoshi et al. 2010). Collectively, the mission of CCN2 in the growth plate is to promote all of the steps of bone formation in a harmonized manner (Kubota and Takigawa 2007). These indications are firmly supported by the phenotype of ccn2null mice. In such mice, the growth plate is characterized by an abnormal morphological appearance with an enlarged hypertrophic layer (Ivkovic et al. 2003). From functional aspects, endochondral ossification is on the whole delayed; and ECM production is depressed therein, which features are accompanied, interestingly, by an unusual induction of CCN3 with counteracting functions (Kawaki et al. 2008a). Such a role of CCN2 in endochondral ossification is also represented by the fact that $\mathrm{CCN} 2$ accelerates bone regeneration (Kikuchi et al. 2008), in which endochondral ossification recurs (Nakata et al. 2002).

These pleiotropic effects of $\mathrm{CCN} 2$ on chondrocytes are known to be mediated by multiple intracellular second messengers of signal transduction, which include protein kinase $\mathrm{C}$ (PKC); mitogen-activated protein kinases (MAPKs) such as p38MAPK, extracellular regulated protein kinase (ERK), and $c$-Jun N-terminal kinase (JNK); phosphoinositide 3-kinase (PI3K); and protein kinase B (PKB) (Yosimichi et al. 2006). CCN2 supposedly ignites these signaling pathways either directly via cell-surface receptors or indirectly via other extracellular cofactors, resulting in the initiation of these multiple signaling cascades.

\section{CCN2 in Meckel's cartilage}

Meckel's cartilage arises from mesodermal progenitor cells situated in close proximity to the zone of mineralization 


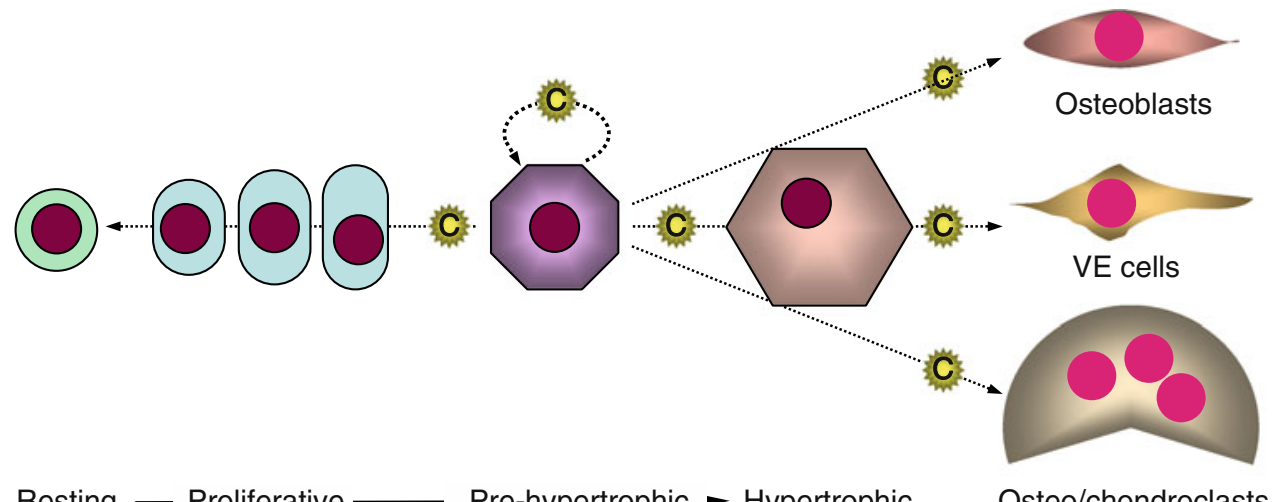

Promotion of cartilage growth

Promotion of ossification

Fig. 3 Endochondral ossification by growth plate cartilage and role of CCN2. Inside of long bones, chondrocytes in the growth plate undergo a series of differentiation processes to execute the bone growth. CCN2 is mainly produced by growth plate chondrocytes in the prehypertrophic and hypertrophic layers and infiltrates through the ECM in both directions. Chondrocytes located most distantly from the $\mathrm{CCN} 2$ producers are less stimulated by $\mathrm{CCN} 2$ and stay at rest. Those located nearby the prehypertrophic ones are strongly stimulated in a matricrine manner to proliferate and maturate to produce cartilaginous ECM, which confers longitudinal bone growth. Prehypertrophic chondrocytes themselves are stimulated by $\mathrm{CCN} 2$ in an autocrine/ intracrine manner and forwarded to terminal differentiation toward apoptosis. CCN2 released to the bone marrow acts on osteoblasts, vascular endothelial (VE) cells, and osteoclasts to promote the replacement of cartilaginous tissue with vascularized bone and bone remodeling. C: CCN2 molecule during mandibular bone formation (Couly et al. 1993). The chondrocytes involved therein also go through a differentiation process similar to that of growth plate chondrocytes; however, Meckel's cartilage never calcifies itself. Interestingly, in spite of the jaw-like shape of the Meckel's cartilage, the mineralized jaw is constructed by an intramembranous ossification process occurring at a zone facing the cartilage (Mina 2001); and, thereafter, Meckel's cartilage disappears. The fate of this transient cartilage is reminiscent of that of the notochord, which leaves the nucleus pulposus as its memento. Of note, nucleus pulposus cells also produce CCN2 (Erwin et al. 2006)

The role of CCN2 in Mechel's cartilage was investigated and reported in 2004 by Shimo et al. Enhanced ccn2 expression is observed in 2 distinct developmental stages, one being mesenchymal condensation and the other, hypertrophic-like late differentiation. Also, application of recombinant $\mathrm{CCN} 2$ (rCCN2) to cultured chondrocytes isolated from Meckel's cartilage stimulates the condensation and later differentiation of those cells (Shimo et al. 2004). It should be noted that CCN2 acts through the ECM on the proximal cell population and promotes the differentiation and proliferation of osteoblasts. Although Meckel's cartilage itself does not metamorphose into mandibular bone, the hypertrophic chondrocytes therein produce CCN2 that recruits osteoblasts and promotes bone formation. Therefore, basically, the roles of chondrocytes and CCN2 in intramembranous jaw bone formation may not remarkably differ from those in the growth plate.

\section{CCN2 in articular cartilage}

Articular cartilage is the permanent cartilage that enables the flexible movement between bones connected by a joint. Like growth-plate cartilage, this tissue originates from the same cartilage anlagen, but remains unmineralized at the end of the bone even after the completion of skeletal growth (Karaplis 2002). Thus, chondrocytes in this type of cartilage do not undergo hypertrophic differentiation towards calcification, except under pathological conditions. The most common pathological change found clinically in articular cartilage is osteoarthritis (OA). After a long time of mechanical overload or another equivalent stimulus, articular cartilage is damaged physically and by inflammation, which damage is accompanied by cluster formation and abnormal hypertrophic changes in chondrocytes, eventually forming osteophytes.

In early studies, CCN2 was found to promote the proliferation and maturation of articular chondrocytes (Nishida et al. 2002); however, in contrast to the growthplate chondrocytes, this factor does not promote the hypertrophic differentiation of articular chondrocytes. In $\mathrm{OA}$ cartilage, overexpression of $\mathrm{CCN} 2$ is frequently observed among the OA articular chondrocytes forming clusters (Omoto et al. 2004). Considering these findings taken together, it is hypothesized that $\mathrm{CCN} 2$ is produced by articular chondrocytes in response to OA injury, in order to regenerate the damaged cartilage by promoting the proliferation of and ECM synthesis by articular chondrocytes 


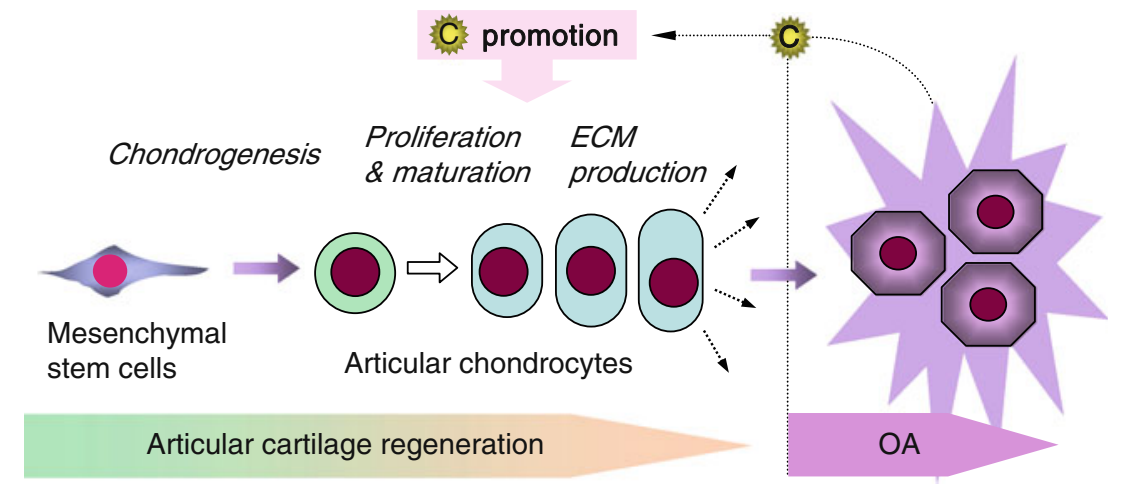

Fig. $4 \mathrm{CCN} 2$ in articular cartilage under physiological and pathological situations. CCN2 is known to promote all of the physiological steps towards articular cartilage formation without promoting pathological hypertrophic changes in articular chondrocytes (right). In osteoarthritis $(\mathrm{OA})$ cartilage, $\mathrm{CCN} 2$ production is strongly induced in articular chondrocytes in order to increase the cell number and compensate the ECM deficiency, which results in the formation of the chondrocyte clusters typically observed in OA cartilage. This hypothetical action of $\mathrm{CCN} 2$ in articular cartilage is strongly supported by the fact that CCN2 regenerates the tissue lost in a fullthickness defect of articular cartilage in vivo. C: $\mathrm{CCN} 2$ molecule

bones are directly formed by osteoblasts without passing through the cartilaginous stage, which is called intramembranous ossification. In this process, osteoblasts are differentiated directly from the nodules of condensed mesenchymal stem cells to deposit type I collagen and calcifying ECM components (Karaplis 2002). During the course of animal evolution, the exoskeleton was developed earlier than the endoskeleton. The former is constructed without cartilaginous anlagen, whereas the prototype of the latter is cartilage. This fundamental difference between these 2 types of bones is seen in Brachyura (Crab), which has a strong calcified exoskeleton and minor cartilaginous endoskeleton. Therefore, the cranial bones surrounding the brain may be regarded as working fossils in our skeleton.

Interestingly, a prototypic gene of $c \mathrm{cn} 2$ can be found even in the genome of Drosophila melanogaster (fruit fly), which has no endoskeleton, suggesting a basic role of CCN2 in general skeletogenesis. Consistent with such an assumption and the fact that $\mathrm{CCN} 2$ promotes the formation, proliferation, and differentiation of osteoblasts in vitro (Nishida et al. 2000; Safadi et al. 2003; Smerdel-Ramoya et al. 2008), CCN2 was found to be required for proper intramembranous ossification in vivo and in vitro through studies on conventional and conditional ccn2-null mice (Kawaki et al. 2008b; Canalis et al. 2010). Furthermore, the attenuated ossifying ability of ccn2-null osteoblasts is rescued by exogenously added rCCN2 (Kawaki et al. 2008b). Thus, CCN2 is now considered to conduct the formation of all of the skeletal parts, following the proper scenario given to each part.

\section{Gene regulation during chondrocyte differentiation}

As stated in other subsections, during the course of the differentiation after mesenchymal condensation, strong

through endochondral ossification, clavicle and cranial 
induction of CCN2 occurs, preceding the hypertrophic differentiation of chondrocytes. The mechanism that induces the $c c n 2$ gene has been investigated at both transcriptional and post-transcriptional levels. Although a number of studies have been performed to clarify the transcriptional regulatory system of the CCN2 gene in various cells, relevant studies with chondrocytic cells are limited (Leask and Abraham 2006; Kubota and Takigawa 2007). However, posttranscriptional regulation of $c c n 2$ has been investigated, usually in the context of chondrocyte biology. The findings currently available on this issue are summarized in Fig. 5.

It is widely recognized that $\mathrm{CCN} 2$ production is strongly induced by TGF- $\beta$ via a transcriptional mechanism (Leask and Abraham 2006). Also in chondrocytes, this regulation appears dominant; and it was reported that the induction of $c c n 2$ by TGF- $\beta$ is partly dependent on the known cis-acting sequence in the $C c n 2$ proximal promoter. This induction could be the net effect of the direct action by TGF- $\beta$ and an indirect effect through endothelin 1. Of further interest, another transcriptional enhancer dominant in chondrocytes (TRENDIC) has been identified (Eguchi et al. 2002). TRENDIC is also located in the proximal promoter region and mediates $c c n 2$ induction in a stronger manner in chondrocytes than in other types of the cells. Subsequent study identified matrix metalloproteinase 3 (MMP-3) as being a TRENDIC-binding protein (Eguchi et al. 2008).
Surprisingly, this report thus unveiled this unexpected functional property of MMP-3, which had been previously regarded only as an ECM-degradating enzyme.

Hypoxic regulation of $\mathrm{CCN} 2$ production is known to occur in chondrocytic cells, in which a post-transcriptional regulatory element in the 3 '-untranslated region, termed cisacting element of structure-anchored repression (CAESAR), mediates the regulation of the mRNA stability by a CAESAR-binding protein (Kubota et al. 2000; Kondo et al. 2006). Contribution of post-transcriptional regulatory events to the stage-specific induction of $\mathrm{CCN} 2$ during chondrocytic differentiation was investigated with chicken embryonic chondrocytes. Then, nucleophosmin (NPM/ B23) was re-discovered as being a specific RNA-binding regulator of the degradation of $c c n 2$ mRNA. According to this study, down-regulation of NPM, which had been previously known only as a histone chaperon, eventually stabilizes the $c c n 2$ mRNA to increase the steady-state level of the mRNA upon hypertrophic differentiation (Mukudai et al. 2008). This regulation is mediated by a cis-element in the $3^{\prime}$-UTR other than CAESAR and, interestingly, is chondrocyte specific. Additionally, a recent report indicated a repressive effect on the chondrocyte phenotype by a micro RNA (Siomi and Siomi 2009), miR-18a, which is mediated, at least in part, through translational repression of the Ccn2 mRNA (Ohgawara et al. 2009). All of these post-

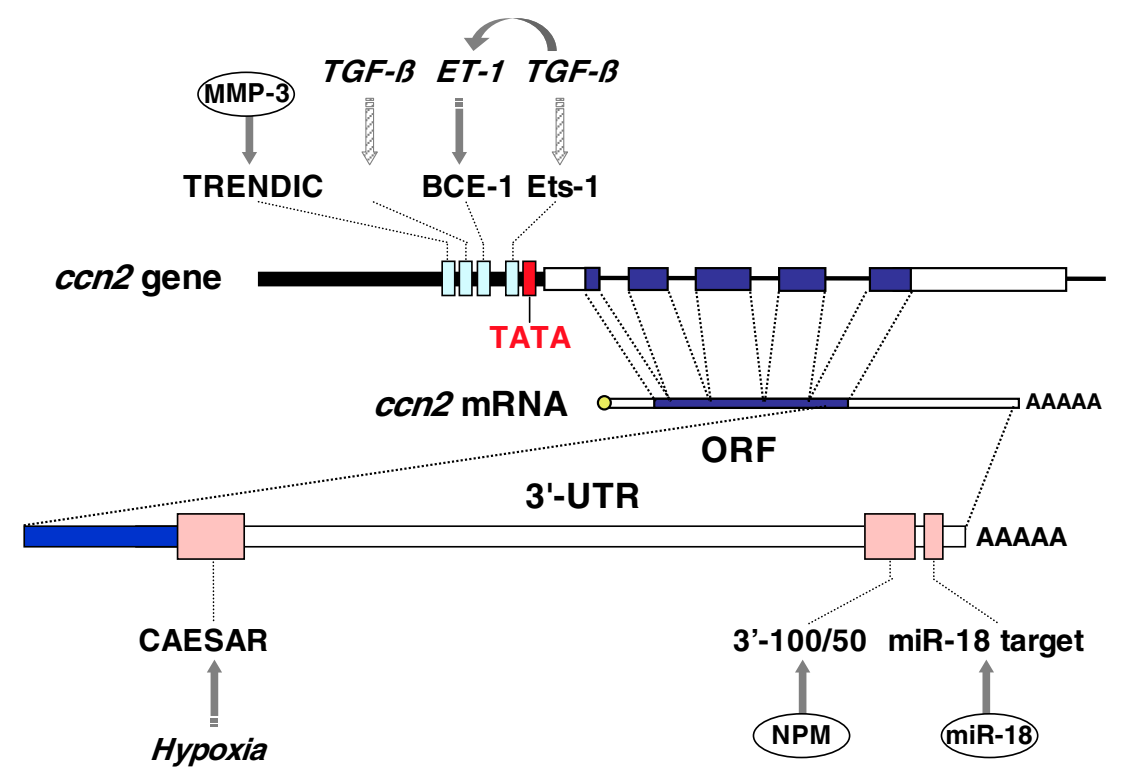

Fig. 5 Transcriptional and post-transcriptional regulation of the CCN2 gene in chondrocytes. Transcriptional regulation observed in chondrocytes or chondrocytic cells is summarized in the upper-half, while post-transcriptional regulation is schematized in the lower half. TGF- $\beta$ is known to enhance the CCN2 expression in chondrocytes, as well as in a number of other types of cells. This regulation is supposedly mediated by 3 genetic cis-elements: Smad-binding element (SBE), basal control element (BCE), and Ets1-binding sequence in the proximal promoter, directly or indirectly through endothelin-1 (ET-1). Hatched arrows indicate the actions experimen- tally indicated from studies using non-chondrocytic cells. MMP-3 is shown to directly bind to TRENDIC to enhance transcription. The RNA stability and translation of the CCN2 mRNA is regulated by direct interaction with nucleophosmin (NPM) and miR-18a through their specific targets in the 3 '-untranslated region (UTR). The cisacting element of structure-anchored repression (CAESAR) mediates the post-transcriptional regulation by factor(s) yet to be identified. TATA, ORF and AAAAA represent the TATA box, open reading frame and polyadenyl tail, respectively 
transcriptional regulations take place in the 3'-UTR, which is consistent with the fundamental rule of gene regulation that has been conserved throughout animal evolution (Merritt et al. 2008). In addition, retinoic acid drastically increases the steady-state level of $c c n 2$ mRNA specifically in hypertrophic chondrocytes through MAPK-mediated signaling, although its precise mechanism remains to be clarified (Shimo et al. 2005)

\section{Medical utility of CCN2 and its derivatives}

As introduced above, the molecular actions of $\mathrm{CCN}$ family members are based on multiple interactions with numerous molecules, which support the integrated and harmonized promotion of tissue development. Therefore, CCN2 is thought to be an ideal molecule to be utilized in the regenerative therapy of various types of cartilages and bone. The utility of CCN2 in the regeneration of damaged articular cartilage and bone was already proven in vivo (Nishida et al. 2004; Kikuchi et al. 2008; Ono et al. 2008), which may lead to the development of a novel anti-OA therapeutic. Similarly, CCN2 may possibly be employed to construct a bioengineered pinna ex vivo for plastic surgery. Moreover, if we could control the CCN2 in the growth plate, we may be able to control body height and shape during the growing period, which may be called "skeletal designing."

Acknowledgements This study was supported by grants from the program Grants-in-aid for Scientific Research (S) [to M.T.], and (C) [to S.K.] from the Japan Society for the Promotion of Science.

Open Access This article is distributed under the terms of the Creative Commons Attribution Noncommercial License which permits any noncommercial use, distribution, and reproduction in any medium, provided the original author(s) and source are credited.

\section{References}

Abreu JG, Ketpura NI, Reversade B, De Robertis EM (2002) Connective-tissue growth factor (CTGF) modulates cell signalling by BMP and TGF-beta. Nat Cell Biol 4:599-604

Aoyama E, Hattori T, Hoshijima M, Araki D, Nishida T, Kubota S, Takigawa M (2009) N-terminal domains of CCN family 2/ connective tissue growth factor bind to aggrecan. Biochem $\mathrm{J}$ 420:413-420

Asaumi K, Nakanishi T, Asahara H, Inoue H, Takigawa M (2000) Expression of neurotrophins and their receptors (TRK) during fracture healing. Bone 26:625-633

Bradham DM, Igarashi A, Potter RL, Grotendorst GR (1991) Connective tissue growth factor: a cysteine-rich mitogen secreted by human vascular cells is related to the SRC-induced immediate early gene product CEF-10. J Cell Biol 114:1285-1294

Brigstock DR, Goldschmeding R, Katsube K, LamSCT LLF, Lyons K, Naus C, Perbal B, Riser B, Takigawa M, Yeger H (2003) Proposal for a unified CCN nomenclature. Mol Pathol 56:127-128
Canalis E, Zanotti S, Beamer WG, Economides AN, Smerdel-Ramoya A (2010) Connective tissue growth factor is required for skeletal development and postnatal skeletal homeostasis in male mice. Endocrinology 151:3490-3501

Chen CC, Lau LF (2009) Functions and mechanisms of action of CCN matricellular proteins. Int J Biochem Cell Biol 41:771-83

Chen L, Charrier AL, Leask A, French SW, Brigstock DR (2011) Ethanol-stimulated differentiated functions of human or mouse hepatic stellate cells are mediated by connective tissue growth factor. J Hepatol, in press. doi:10.1016/j.jhep.2010.11.025

Cicha I, Garlichs CD, Daniel WG, Goppelt-Struebe M (2004) Activated human platelets release connective tissue growth factor. Thromb Haemost 91:755-760

Couly GF, Coltey PM, Le Douarin NM (1993) The triple origin of skull in higher vertebrates: a study in quail-chick chimeras. Development 117:409-429

Eguchi T, Kubota S, Kondo S, Kuboki T, Yatani H, Takigawa M (2002) A novel cis-element that enhances connective tissue growth factor gene expression in chondrocytic cells. Biochem Biophys Res Commun 295:445-451

Eguchi T, Kubota S, Kawata K, Mukudai Y, Uehara J, Ohgawara T, Ibaragi S, Sasaki A, Kuboki T, Takigawa M (2008) Novel transcription-factor-like function of human matrix metalloproteinase 3 regulating the $\mathrm{CTGF} / \mathrm{CCN} 2$ gene. Mol Cell Biol 28:2391-2413

Erwin WM, Ashman K, O’Donnel P, Inman RD (2006) Nucleus pulposus notochord cells secrete connective tissue growth factor and up-regulate proteoglycan expression by intervertebral disc chondrocytes. Arthritis Rheum 54:3859-3867

Fujisawa T, Hattori T, Ono M, Uehara J, Kubota S, Kuboki T, Takigawa M (2008) CCN family $2 /$ connective tissue growth factor (CCN2/CTGF) stimulates proliferation and differentiation of auricular chondrocytes. Osteoarthritis Cartilage 16:787-795

Gao R, Brigstock DR (2004) Connective tissue growth factor (CCN2) induces adhesion of rat activated hepatic stellate cells by binding of its C-terminal domain to integrin alpha(v)beta(3) and heparan sulfate proteoglycan. J Biol Chem 279:8848-8855

Hoshijima M, Hattori T, Aoyama E, Nishida T, Yamashiro T, Takigawa M (2011) CCN3/NOV forms heterodimers with CCN2/CTGF and impairs collagen II and aggrecan synthesis by chondrocytes. Abstract of the $24^{\text {th }}$ Annual Meeting of the Japanese Society of Cartilage Metabolism

Hoshijima M, Hattori T, Inoue M, Araki D, Hanagata H, Miyauchi A, Takigawa M (2006) CT domain of CCN2/CTGF directly interacts with fibronectin and enhances cell adhesion of chondrocytes through integrin alpha5beta1. FEBS Lett 580:1376s-82

Inoki I, Shiomi T, Hashimoto G, Enomoto H, Nakamura H, Makino K, Ikeda E, Takata S, Kobayashi K, Okada Y (2002) Connective tissue growth factor binds vascular endothelial growth factor (VEGF) and inhibits VEGF-induced angiogenesis. FASEB J 16:219-221

Itoh S, Hattori T, Tomita N, Aoyama E, Yamashiro T, Takigawa M (2010) Cartilage-specific overexpression of CCN2/CTGF protects articular cartilage from age-related osteoarthritis-like changes. Abstract of the $6^{\text {th }}$ International CCN Workshop

Ivkovic S, Yoon BS, Popoff SN, Safadi FF, Libuda DE, Stephenson RC, Daluiski A, Lyons KM (2003) Connective tissue growth factor coordinates chondrogenesis and angiogenesis during skeletal development. Development 130:2779-2791

Jedsadayanmata A, Chen CC, Kireeva ML, Lau LF, Lam SC (1999) Activation-dependent adhesion of human platelets to Cyr61 and Fisp12/mouse connective tissue growth factor is mediated through integrin alpha(Ilb)beta(3). J Biol Chem 274:24321-24327

Karaplis AC (2002) Embryonic development of bone and the molecular regulation of intramembranous and endochondral bone formation. In: Bilezikian JP, Raisz LG, Rodan GA (eds) Principles of bone biology, vol. 1. Academic Press, New York, pp 33-58 
Kawaki H, Kubota S, Suzuki A, Lazar N, Yamada T, Matsumura T, Ohgawara T, Maeda T, Perbal B, Lyons KM, Takigawa M (2008a) Cooperative regulation of chondrocyte differentiation by $\mathrm{CCN} 2$ and $\mathrm{CCN} 3$ shown by a comprehensive analysis of the $\mathrm{CCN}$ family proteins in cartilage. J Bone Miner Res 23:1751-1764

Kawaki H, Kubota S, Suzuki A, Yamada T, Matsumura T, Mandai T, Yao M, Maeda T, Lyons KM, Takigawa M (2008b) Functional requirement of $\mathrm{CCN} 2$ for intramembranous bone formation in embryonic mice. Biochem Biophys Res Commun 366:450-456

Kawata K, Eguchi T, Kubota S, Kawaki H, Oka M, Minagi S, Takigawa M (2006) Possible role of LRP1, a CCN2 receptor, in chondrocytes. Biochem Biophys Res Commun 345:552-559

Kikuchi T, Kubota S, Asaumi K, Kawaki H, Nishida T, Kawata K, Mitani S, Tabata Y, Ozaki T, Takigawa M (2008) Promotion of bone regeneration by $\mathrm{CCN} 2$ incorporated into gelatin hydrogel. Tissue Eng Part A 14:1089-1098

Kondo S, Kubota S, Mukudai Y, Moritani N, Nishida T, Matsushita H, Matsumoto S, Sugahara T, Takigawa M (2006) Hypoxic regulation of stability of connective tissue growth factor/CCN2 mRNA by 3'-untranslated region interacting with a cellular protein in human chondrosarcoma cells. Oncogene 25:1099-110

Kubota S, Takigawa M (2007) Role of CCN2/CTGF/Hcs24 in bone growth. Int Rev Cytol 257:1-41

Kubota S, Kondo S, Eguchi T, Hattori T, Nakanishi T, Pomerantz RJ, Takigawa M (2000) Identification of an RNA element that confers post-transcriptional repression of connective tissue growth factor/hypertrophic chondrocyte specific 24 (ctgf/hcs24) gene: similarities to retroviral RNA-protein interactions. Oncogene 19:4773-4786

Kubota S, Kawata K, Yanagita T, Doi H, Kitoh T, Takigawa M (2004) Abundant retention and release of connective tissue growth factor (CTGF/CCN2) by platelets. J Biochem 136:279-282

Leask A, Abraham DJ (2006) All in the CCN family: essential matricellular signaling modulators emerge from the bunker. J Cell Sci 119:4803-4810

Leask A, Parapuram SK, Shi-Wen X, Abraham DJ (2009) Connective tissue growth factor (CTGF, CCN2) gene regulation: a potent clinical bio-marker of fibroproliferative disease? J Cell Commun Signal 3:89-94

Maeda A, Nishida T, Aoyama E, Kubota S, Lyons KM, Kuboki T, Takigawa M (2009) CCN family 2/connective tissue growth factor modulates BMP signalling as a signal conductor, which action regulates the proliferation and differentiation of chondrocytes. J Biochem 145:207-216

Merritt C, Rasoloson D, Ko D, Seydoux G (2008) 3' UTRs are the primary regulators of gene expression in the $\mathrm{C}$. elegans germline. Curr Biol 18:1476-1482

Mina M (2001) Regulation of mandibular growth and morphogenesis. Crit Rev Oral Biol Med 12:276-300

Mukudai Y, Kubota S, Kawaki H, Kondo S, Eguchi T, Sumiyoshi K, Ohgawara T, Shimo T, Takigawa M (2008) Posttranscriptional regulation of chicken ccn2 gene expression by nucleophosmin/ B23 during chondrocyte differentiation. Mol Cell Biol 28:61346147

Nakanishi T, Kimura Y, Tamura T, Ichikawa H, Yamaai Y, Sugimoto T, Takigawa M (1997) Cloning of a mRNA preferentially expressed in chondrocytes by differential display-PCR from a human chondrocytic cell line that is identical with connective tissue growth factor (CTGF) mRNA. Biochem Biophys Res Commun 234:206-210

Nakanishi T, Nishida T, Shimo T, Kobayashi K, Kubo T, Tamatani T, Tezuka K, Takigawa M (2000) Effects of CTGF/Hcs24, a product of a hypertrophic chondrocyte-specific gene, on the proliferation and differentiation of chondrocytes in culture. Endocrinology 141:264-273
Nakata E, Nakanishi T, Kawai A, Asaumi K, Yamaai T, Asano M, Nishida T, Mitani S, Inoue H, Takigawa M (2002) Expression of connective tissue growth factor/hypertrophic chondrocytespecific gene product $24(\mathrm{CTGF} / \mathrm{Hcs} 24)$ during fracture healing. Bone 31:441-447

Nishida T, Nakanishi T, Asano M, Shimo T, Takigawa M (2000) Effects of $\mathrm{CTGF} / \mathrm{Hcs} 24$, a hypertrophic chondrocyte-specific gene product, on the proliferation and differentiation of osteoblastic cells in vitro. J Cell Physiol 184:197-206

Nishida T, Kubota S, Nakanishi T, Kuboki T, Yosimichi G, Kondo S, Takigawa M (2002) CTGF/Hcs24, a hypertrophic chondrocytespecific gene product, stimulates proliferation and differentiation, but not hypertrophy of cultured articular chondrocytes. J Cell Physiol 192:55-63

Nishida T, Kubota S, Fukunaga T, Kondo S, Yosimichi G, Nakanishi T, Takano-Yamamoto T, Takigawa M (2003) CTGF/Hcs24, hypertrophic chondrocyte-specific gene product, interacts with perlecan in regulating the proliferation and differentiation of chondrocytes. J Cell Physiol 196:265-275

Nishida T, Kubota S, Kojima S, Kuboki T, Nakao K, Kushibiki T, Tabata Y, Takigawa M (2004) Regeneration of defects in articular cartilage in rat knee joints by $\mathrm{CCN} 2$ (connective tissue growth factor). J Bone Miner Res 19:1308-1319

Nishida T, Emura K, Kubota S, Lyons KM, Takigawa M. (2011). $\mathrm{CCN}$ family $2 /$ connective tissue growth factor (CCN2/CTGF) promotes osteoclastogenesis via induction of and interaction with dendritic cell-specific transmembrane protein (DC-STAMP). J Bone Miner Res, in press.

Ohgawara T, Kubota S, Kawaki H, Kondo S, Eguchi T, Kurio N, Aoyama E, Sasaki A, Takigawa M (2009) Regulation of chondrocytic phenotype by micro RNA 18a: involvement of $\mathrm{Ccn} 2 / \mathrm{Ctgf}$ as a major target gene. FEBS Lett 583:10061010

Omoto S, Nishida K, Yamaai Y, Shibahara M, Nishida T, Doi T, Asahara H, Nakanishi T, Inoue H, Takigawa M (2004) Expression and localization of connective tissue growth factor (CTGF/Hcs24/CCN2) in osteoarthritic cartilage. Osteoarthritis Cartilage 12:771-778

Ono M, Kubota S, Fujisawa T, Sonoyama W, Kawaki H, Akiyama K, Shimono K, Oshima M, Nishida T, Yoshida Y, Suzuki K, Takigawa M, Kuboki T (2008) Promotion of hydroxyapatiteassociated, stem cell-based bone regeneration by CCN2. Cell Transplant 17:231-240

Perbal B (2004) CCN proteins: multifunctional signalling regulators. Lancet 363:62-64

Perbal B, Takigawa M (2005) CCN protein -A new family of cell growth and differentiation regulators. Imperial College Press, London, pp 1-311

Safadi FF, Xu J, Smock SL, Kanaan RA, Selim AH, Odgren PR, Marks SC Jr, Owen TA, Popoff SN (2003) Expression of connective tissue growth factor in bone: its role in osteoblast proliferation and differentiation in vitro and bone formation in vivo. J Cell Physiol 196:51-62

Segarini PR, Nesbitt JE, Li D, Hays LG, Yates JR 3rd, Carmichael DF (2001) The low density lipoprotein receptor-related protein/ alpha2-macroglobulin receptor is a receptor for connective tissue growth factor. J Biol Chem 276:40659-40667

Shimo T, Nakanishi T, Nishida T, Asano M, Kanyama M, Kuboki $\mathrm{T}$, Tamatani $\mathrm{T}$, Tezuka $\mathrm{K}$, Takemura $\mathrm{M}$, Matsumura $\mathrm{T}$, Takigawa M (1999) Connective tissue growth factor induces the proliferation, migration and tube formation of vascular endothelial cells in vitro, and angiogenesis in vivo. J Biochem 126:137-145

Shimo T, Kanyama M, Wu C, Sugito H, Billings PC, Abrams WR, Rosenbloom J, Iwamoto M, Pacifici M, Koyama E (2004) 
Expression and roles of connective tissue growth factor in Meckel's cartilage development. Dev Dyn 231:136-147

Shimo T, Koyama E, Sugito H, Wu C, Shimo S, Pacifici M (2005) Retinoid signaling regulates CTGF expression in hypertrophic chondrocytes with differential involvement of MAP kinases. J Bone Miner Res 20:867-877

Siomi H, Siomi MC (2009) On the road to reading the RNAinterference code. Nature 457:396-404

Smerdel-Ramoya A, Zanotti S, Deregowski V, Canalis E (2008) Connective tissue growth factor enhances osteoblastogenesis in vitro. J Biol Chem 283:22690-22699

Sumiyoshi K, Kubota S, Furuta RA, Yasui K, Aoyama E, Kawaki H, Kawata K, Ohgawara T, Yamashiro T, Takigawa M (2010) Thrombopoietic-mesenchymal interaction that may facilitate both endochondral ossification and platelet maturation via CCN2. J Cell Commun Signal 4:5-14

Takigawa M, Tajima K, Pan HO, Enomoto M, Kinoshita A, Suzuki F, Takano Y, Mori Y (1989) Establishment of a clonal human chondrosarcoma cell line with cartilage phenotypes. Cancer Res 49(3):996-4002

Wahab NA, Weston BS, Mason RM (2005) Connective tissue growth factor $\mathrm{CCN} 2$ interacts with and activates the tyrosine kinase receptor TrkA. J Am Soc Nephrol 16:340351

Yosimichi G, Kubota S, Nishida T, Kondo S, Yanagita T, Nakao K, Takano-Yamamoto T, Takigawa M (2006) Roles of PKC, PI3K and JNK in multiple transduction of CCN2/CTGF signals in chondrocytes. Bone 38:853-863 